\title{
Endoscopic Treatment of a Large Upper Gastrointestinal Anastomotic Leak Using a Prolene Plug and Cyanoacrylate
}

Anastomotic leaks occur in up to $20 \%$ of patients after upper gastrointestinal surgery, and they represent a significant source of postoperative morbidity and mortality. The treatment options include surgery, conservative treatment, or endoscopic treatment. In this report, we present the case of a patient who was successfully treated with a combination of a Prolene (polypropylene) plug and cyanoacrylate.

A 64-year-old man had undergone subtotal gastrectomy and Billroth II gastrojejunostomy for gastric cancer 1 month previously. On the seventh postoperative day, he underwent repeat surgery due to anastomotic leakage and intra-abdominal sepsis. During the operation, the gastroenterostomy anastomosis was found to be normal, and a leak from the lesser curvature side of the gastric stump was noticed. The gap was sutured and a nasoenteric feeding tube was placed. However, 3 days after the second operation, nutritional solution started to emerge from the abdominal drains. Nasoenteric feeding was switched to total parenteral nutrition, and somatostatin treatment was started.

The leak was still continuing on day 24 after the first operation. An upper endoscopic examination was carried out, which revealed that the suture in the gastric stump located just above the gastrojejunostomy was dehiscent and that a gap approximately $2 \mathrm{~cm}$ wide had formed (Figure 1).

In a second session, a Prolene mesh was folded over on itself and shaped to fit the gap. A transparent cap, of the type used for band ligation, was placed on the tip of the endoscope, and the Prolene mesh was caught in the tip of the endoscope with a biopsy forceps inserted through the working channel. This allowed visualization from the side walls of the cap, and the mesh was stabilized on the endoscope tip (Figure 2).

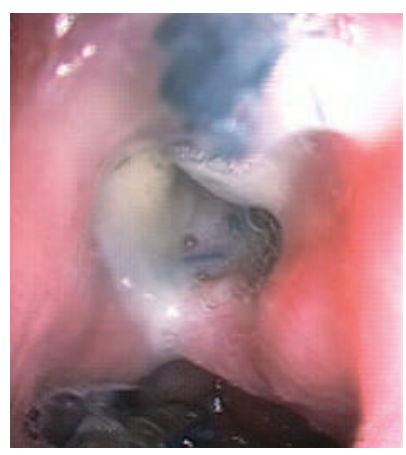

Figure 1 A wide gap is seen at the anastomosis site. Dehiscent suture material at the upper edge and an intra-abdominal drain are visible.

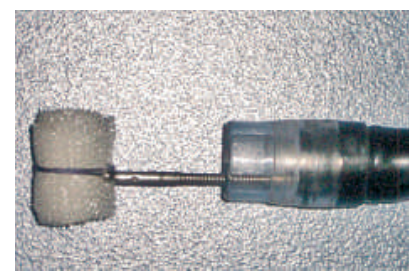

Figure 2 After the placement of a transparent cap on the tip of the endoscope, the plug made of Prolene mesh is caught with a biopsy forceps and stabilized at the tip of the endoscope.

The endoscope was inserted through an overtube, and after the mesh had been placed in the gap, a mixture of $0.7 \mathrm{ml} \mathrm{Li}$ piodol and $0.5 \mathrm{ml}$ cyanoacrylate was injected to attach the plug. No procedural complications were observed. Two days after the procedure, endoscopy (Figure 3) and a water-soluble contrast study were carried out, which revealed no leakage. The patient resumed oral food intake and was discharged. At a follow-up visit 2 months later, he was clinically well and had gained $6 \mathrm{~kg}$ in weight. An endoscopic check-up examination showed that the surface of the mesh had epithelialized, forming a polypoid structure that did not obstruct food passage (Figure 4).

The option of endoscopic treatment is increasingly being preferred in suitable patients with postoperative anastomotic leaks and fistulas. There have been case

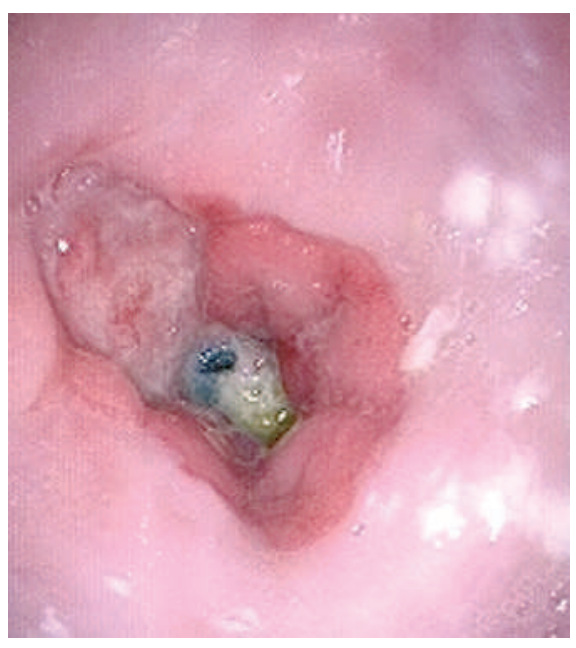

Figure 3 The endoscopic view 2 days after the procedure. The plug is tightly adjacent to the entrance of the leak.

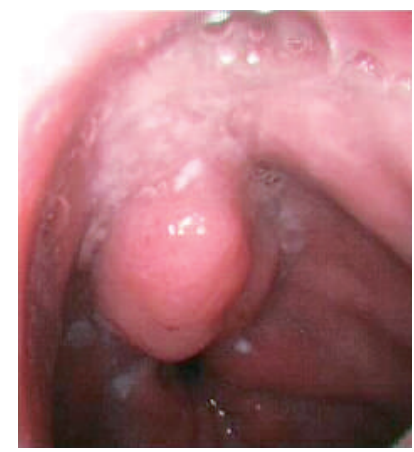

Figure 4 The endoscopic view 2 months after the procedure. The leakage site is completely closed, and a polypoid mass formed by epithelialization of the mesh is seen.

reports of fistulas being closed by endoscopic clip application [1], band ligation and Endoloop application [2], stent placement [3], fibrin glue [4], and a collagen plug [5]. In a recent study, postoperative upper gastrointestinal fistulas or leaks were managed successfully in seven of nine patients by using a combination of fibrin glue and a Vicryl plug [6].

A Medline research in September 2004 revealed that the present case is the first in which an anastomotic leak was successfully treated using a combination of a Prolene plug and cyanoacrylate. Endoscopic treatment may be an alternative to sur- 
gery for wide anastomotic leaks in endoscopically accessible locations.

\section{S. Disibeyaz ${ }^{1}$, E. Parlak1, A. S. Koksal' ${ }^{1}$,} B. Cicek², U. Koc², B. Sahin'

${ }^{1}$ Dept. of Gastroenterology, Türkiye Yüksek İhtisas Hospital, Ankara, Turkey

2 Dept. of General Surgery, Ankara Numune Training and Research Hospital, Ankara, Turkey

\section{References}

${ }^{1}$ Familiari P, Macri A, Consolo Pet al. Endoscopic clipping of a colocutaneous fistula following necrotizing pancreatitis: case report. Dig Liver Dis 2003; 35: 907-910

${ }^{2}$ Will U, Meyer F, Hartmeier Set al. Endoscopic treatment of a pseudocystocolonic fistula by band ligation and Endoloop application: case report. Gastrointest Endosc 2004; 59: $581-583$
${ }^{3}$ Laasch HU, Wilbraham L, Marriott Aet al. Treatment of colovaginal fistula with coaxial placement of covered and uncovered stents. Endoscopy 2003; 35: 1081

${ }^{4}$ Gonzalez-Ojeda A, Avalos-Gonzalez J, Mucino-Hernandez Mlet al. Fibrin glue as adjuvant treatment for gastrocutaneous fistula after gastrostomy tube removal. Endoscopy 2004; 36: 337 - 341

${ }^{5}$ Lomis NN, Miller FJ, Loftus TJet al. Refractory abdominal-cutaneous fistulas or leaks: percutaneous management with a collagen plug. J Am Coll Surg 2000; 190: $588-592$

${ }^{6}$ Truong S, Bohm G, Klinge Uet al. Results after endoscopic treatment of postoperative upper gastrointestinal fistulas and leaks using combined Vicryl plug and fibrin glue. Surg Endosc 2004; 18: $1105-1108$
Corresponding Author

\section{S. Disibeyaz, M.D.}

Dept. of Gastroenterology Türkiye Yüksek İhtisas Hospital Selanik Cad. 27/13

Kızılay

Ankara

Turkey

Fax: $\quad$ +90-312-417 7324

E-mail: selcukdisibeyaz@yahoo.com 